Вестник образования и развития науки Российской академии естественных наук, 2018, 22(3): 57-65 (C) С.И. Сороко, 2018

\author{
S.I. Soroko
}

\title{
FEATURES OF TEST-COSMONAUTS' REACTION TO EXPOSURE TO STRESS IN DIFFERENT PERIODS OF LONG ISOLATION IN SPACESHIP SIMULATOR
}

The research has been made in accordance with government assignment of the Institute of Evolutionary Physiology and Biochemistry, Russian Academy of Sciences (№ AAAA-F18-118012290142-9)

Svyatoslav Soroko - Head of the Laboratory of the I. M. Sechenov Institute of Evolutionary Physiology and Biochemistry, Russian Academy of Sciences, corresponding member of the Russian Academy of Sciences, full member of the Russian Academy of Natural Sciences, recipient of the State Prize of the USSR, Doctor of Medicine, professor, St. Petersburg; e-mail: soroko@iephb.ru.

We look at individual features of brain neurodynamics in test-cosmonauts at different stages of adaptation to the conditions of long-term isolation in the Ground experimental complex. Special attention is paid to the reaction of participants of 90- and 120-day experiments to emergencies (accidents concerning the life support systems) as well as the dynamics of interpersonal relationships. We present the data connected with the role of personal attitude collected at the final stage of the experiment. The prognostic significance of the assessment of individual stress resistance and group compatibility for the selection of people for further work in the conditions of autonomous existence of small groups (cosmonauts, submariners, polar explorers, small military units) is shown.

Keywords: adaptation; space flight modeling; social isolation; stress resistance; group compatibility; nervous system plasticity; medical and physiological selection.

\author{
С.И. Сороко
}

\section{ОСОБЕННОСТИ РЕАКЦИИ ИСПЫТАТЕЛЕЙ НА СТРЕССОВЫЕ ВОЗДЕЙСТВИЯ В РАЗНЫЕ ПЕРИОДЫ ДЛИТЕЛЬНОЙ ИЗОЛЯЦИИ В МОДЕЛИ КОСМИЧЕСКОГО КОРАБЛЯ}

\author{
Работа выполнена в рамках госзадания ИЭФБ РАН
}

(рег. № AAAA-Ф18-118012290142-9)

Святослав Иосифович Сороко - зав. лабораторией Института эволюционной физиологии и биохимии им. И.М. Сеченова Российской академии наук, член-корреспондент РАН, действительный член РАЕН, лауреат Государственной премии СССР, доктор медицинских наук, профессор, г. Санкт-Петербург; e-mail: soroko@iephb.ru.

В статье рассматриваются индивидуальные особенности нейродинамики мозга испытателей на разных стадиях адаптации к условиям длительной изоляции в Наземном экспериментальном комплексе. Особое внимание уделено реакции участников 90- $и$ 120-суточного экспериментов на внезапные нештатные ситуации (аварии систем жизнеобеспечения), динамику межличностных отношений. Приведены данные о роли личностной установки на окончание эксперимента. Показана прогностическая значимость оценки индивидуальной стрессоустойчивости и групповой совместимости при отборе лиц для работы в условиях автономного существования малочисленных коллективов (космонавтов, подводников, полярников, небольших воинских подразделений).

Ключевые слова: адаптация; моделирование космических полётов; социальная изоляция; стрессоустойчивость; групповая совместимость; пластичность нервной системы; медико-физиологический отбор. 
Полёты человека в космос и его длительное пребывание на околоземной орбите стали возможными благодаря упорному труду конструкторов, инженеров, физиков, математиков. Однако только технических средств для осуществления этих планов было недостаточно. На первом плане стояла основная проблема сможет ли организм человека физически выдержать большие перегрузки, влияние невесомости. Многочисленные полёты биоспутников и космических кораблей с мелкими и крупными животными показали, что полёты в космос живых существ возможны. Однако потребовались длительные и кропотливые исследования с участием добровольцев-испытателей и кандидатов в космонавты в сурдокамерах, моделях кораблей, на центрифугах, самолётах-лабораториях, чтобы разработать систему отбора, подготовки и жизнеобеспечения человека на кораблях и космических станциях $[5 ; 6 ; 8 ; 9 ; 20]$.

Однако, несмотря на успешные систематические полёты и многолетнее нахождение на околоземной орбите обитаемых космических станций, есть проблемы, решение которых требует проведения дальнейших фундаментальных исследований в модельных экспериментах. К ним, в первую очередь, относятся вопросы индивидуальной стрессоустойчивости и групповой совместимости малочисленных экипажей. Именно от способности космонавтов адаптироваться к сложным факторам космического полёта, умения быстро разрешать личностные и межличностные конфликты без нервных срывов и нарушения качества деятельности во многом зависит выполнение сложной программы полёта, оперативное решение возникающих нештатных ситуаций, представляющих витальную угрозу и досрочное прекращение полёта.

В данной работе представлены не публиковавшиеся ранее материалы по исследованию индивидуальной нервнопсихической устойчивости и групповой совместимости испытателей в условиях длительной изоляции в Наземном экспериментальном комплексе с автономной системой жизнеобеспечения. В предыду- щей работе [15] были рассмотрены динамика биоэлектрической активности мозга этих же испытателей на разных стадиях адаптации без анализа стрессоустойчивости и психологической совместимости. Мы полагаем, что представленные ниже данные существенно расширят существующие представления о зависимости стрессоустойчивости человека от индивидуальных особенностей механизмов саморегуляции мозга и могут быть полезными при отборе лиц для длительной работы малочисленных изолированных коллективов в экстремальных условиях (космонавтов, подводников, полярников, воинских спецподразделений и др.).

Возникновение неожиданных аварийных ситуаций в условиях пребывания в замкнутом изолированном пространстве (особенно неполадки в системах жизнеобеспечения) является сильнейшим стрессогенным фактором, связанным с большой угрозой для жизни экипажа. Известно, что один и тот же стимул может привести к разным стрессорным реакциям в зависимости от предварительной установки и подготовленности человека, от функционального состояния организма, эмоционально-волевых качеств и т.д. [8; 9; $10 ; 14 ; 16 ; 17]$, то есть от индивидуальнотипологических особенностей. В условиях сильной угрозы для жизни у отдельных лиц может возникнуть состояние безнадёжности или, так называемый, «паралич» воспроизведения прежних навыков, который закрывает доступ к информации, позволяющей устранить неполадки [19].

Известно, что не все люди, оказавшиеся в чрезвычайной ситуации (кораблекрушения, аварии самолётов, стихийные бедствия и т.д.), способны сохранить высокий уровень самообладания и принимать правильные решения. Большая часть, 50-75\% потерпевших, сразу же впадают в состояние своеобразного ошеломления, получившего в специальной литературе название «панической реакции» $[10 ; 18]$. В этом состоянии у людей наступает апатия, нежелание совершения действий, безразличие, хотя внешне они выглядят довольно спокойными. У 12 $25 \%$ лиц возникают истерические реак- 
ции, которые у одних проявляются в сильном возбуждении, беспорядочных действиях, у других - сильной заторможенности, порой до полной прострации. По данным известных специалистов в области выживаемости человека в экстремальных условиях [21; 22], только 12-25\% людей способны сохранить самообладание, быстро оценить обстановку и принять правильное решение. Следует, однако, отметить, что спустя некоторое время большая часть людей успокаивается, адаптируется к новой обстановке и оказывается способной действовать адекватно и целенаправленно $[4 ; 10 ; 11]$, особенно в условиях, когда этими действиями начинает руководить неформальный лидер.

Следовательно, существование индивидуальных различий в устойчивости к стрессу позволяет изучать пределы адаптивных возможностей человека в сложных условиях внешней среды, является одной из характеристик индивидуальнотипологических особенностей его центральной нервной системы.

Данная серия экспериментов проводилась в Наземном экспериментальном комплексе (далее - НЭК) на базе Института медико-биологических проблем М3 СССР (ныне - ГНЦ РФ Институт медикобиологических проблем РАН). Наземный экспериментальный комплекс представляет собой модель космического корабля. Это сложное уникальное инженернотехническое сооружение с комплексом систем жизнеобеспечения рассчитано на длительный автономный режим работы с полной изоляцией от окружающей среды. НЭК предназначен для моделирования условий длительных космических полётов и поэтому имеет больший набор помещений и их объем, чем существующие в настоящее время космические корабли. Условия обитания, режима работы, медицинского контроля и управления системой жизнеобеспечения НЭК приведены ранее [15].

Наши исследования в НЭКе проводились во время 90- и 120-суточного экспериментов. Эксперименты отличались как по численности экипажа, так и по условиям их проведения. В 90-суточном экспе- рименте принимало участие трое испытателей: К-ов, А-ин, М-ов. При проведении этого эксперимента испытатели точно знали о его продолжительности. Они были предупреждены, что замена членов экипажа в ходе эксперимента или досрочный выход из объекта практически исключены и могут быть разрешены только в случае серьёзных заболеваний. В 120суточном эксперименте принимало участие шесть испытателей: П-ин, К-ов, Т-ко, А-ин, Кл-ов, Г-ко. По условиям эксперимента была запланирована поочерёдная смена отдельных членов экипажа, причём трое из них должны были работать от начала до конца. Испытателям было неизвестно, кого и в какие сроки будут заменять. Таким образом, никто из членов экипажа фактически заранее не знал, сколько дней ему придётся провести в НЭКе. На заключительном этапе эксперимента в объект на 4 дня вошло ещё 3 человека из числа сотрудников, проводивших эксперимент.

В течение экспериментов температура воздуха в жилом отсеке составляла плюс $20 \pm 5^{\circ} \mathrm{C}$, относительная влажность - 60$30 \%$, концентрация кислорода равнялась $19,7-21 \%$, углекислого газа - 1,1-2\%. Содержание вредных примесей в окружающей атмосфере (окись углерода, аммиак, аминосоединения, органические примеси, сероводород и т.д.) не превышало уровней, регламентированных программой. Питание испытателей осуществлялось с использованием меню и продуктов, разработанных для реальных космических полётов.

С целью изучения устойчивости испытателей к изменению параметров искусственной газовой атмосферы и возникающему при этом стрессу в ходе эксперимента были предусмотрены четыре внезапные аварийные ситуации (имитация неисправности системы жизнеобеспечения). Из них две аварийные ситуации были ложными, в которых специально изменялись только показания контрольноизмерительных приборов и увеличивалась температура и влажность, процентное соотношение газов в атмосфере было в норме. При моделировании реальных аварий- 
ных ситуаций концентрация кислорода

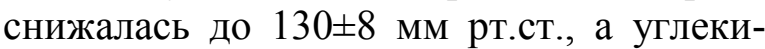
слого газа возрастала до 3,1-3,5\%, температура поддерживалась на уровне плюс 32 $\pm 2{ }^{\circ} \mathrm{C}$, влажность $-95 \%$.

В задачи наших медико-физиологических исследований входило изучение стрессоустойчивости членов экипажа к специально запланированным аварийным ситуациям и техническим неполадкам, психологической совместимости и способности испытателей к разрешению личностных и межличностных конфликтов. Было важно определить, какую роль в этих процессах играют такие свойства центральной нервной системы, как пластичность нейродинамических процессов и индивидуальные типы механизмов саморегуляции мозга.

Анализ полученных данных показал, что во время аварийных ситуаций, которые моделировались в НЭКе в 90суточном эксперименте, происходят определённые сдвиги в функциональном состоянии организма у всех испытателей. Напряжение нервной системы возрастает, о чём свидетельствует значительное увеличение в ЭЭГ тета-ритма. В процессе выполнения произвольной регуляции параметров ЭЭГ и выполнения операторской деятельности в системе зрительномоторного слежения более быстро нарастают признаки утомления: появление в ЭЭГ медленных ритмов (дельта-ритма), сокращение времени успешной регуляции параметров ЭЭГ, увеличение числа ошибок к концу опыта, заметное увеличение времени восстановления параметров ЭЭГ после выполнения той или иной пробы. Выраженность указанных нарушений имеет свои особенности у каждого испытателя.

Следует отметить также тот факт, что влияние второй аварийной ситуации было значительно меньше, чем первой. Имитация аварии в первом и во втором случаях практически не вызывала изменений в состоянии испытателя М-ва. В то время, как у испытателя К-ва (командира экипажа) изменения в ЭЭГ были такими же, как и в случаях реальных аварийных ситуаций, за исключением незначительных особенно- стей.

Рассмотрим более подробно влияние аварийных ситуаций на каждого члена экипажа в отдельности.

Во время моделирования действительных аварийных ситуаций в ЭЭГ К-ва (командир экипажа в 90-суточном эксперименте) отмечается появление медленных высокоамплитудных волн. Дисперсия амплитуды ЭЭГ увеличивается, гистограммы периодов ЭЭГ приобретают бимодальный характер с максимумами в области полосы 5,7-7,8 Гц и 2,6-3,9 Гц.

Произвольная регуляция ЭЭГ и зрительно-моторное слежение вызывали появление в ЭЭГ значительного увеличения тета- и дельта-индексов. Точность слежения была низкой. Однако вряд ли это следует относить только за счёт влияния аварийной ситуации, так как она приходится на период, когда у испытателя отмечалась фаза постепенного улучшения качества операторской деятельности (I период). Оценить качество работоспособности в системе зрительно-моторного слежения во время второй аварийной ситуации у испытателя К-ва не удалось вследствие нарушения работы программно-аппаратного медицинского комплекса внутри объекта для съёма и дистанционной передачи медико-физиологической информации (в том числе и ЭЭГ) при проведении обследования испытателей.

Следует отметить, что выполнение всех функциональных проб осуществлялось при сохранении в ЭЭГ высокого индекса медленных частот. Имитация аварийной ситуации вызывала те же изменения в ЭЭГ. Некоторой особенностью являлось то, что во время ложной аварии отмечается не только увеличение дисперсии амплитуды, но и расширение частотного диапазона ЭЭГ. Если во время действительных аварийных ситуаций отмечалась выраженная депрессия альфа-ритма во всем диапазоне, то во время имитации аварий (особенно во вторую) этого не наблюдается. Во время второй ложной аварии испытатель К-ов достаточно хорошо выполнял произвольную регуляцию ЭЭГ, слежение за огибающей ЭЗГ и заданной кривой. 
В дни первой и второй аварийных ситуаций в ЭЭГ А-на (бортинженер) отмечается наличие медленных колебаний. Частотный спектр смещается в медленную сторону, особенно заметно при выполнении произвольной регуляции и слежения. В дни первой аварии в ЭЭГ сдвиг в медленную сторону был более выражен, чем во вторую аварию. Выполнение задач с произвольной регуляцией параметров ЭЭГ и зрительно-моторным слежением за огибающей амплитуды ЭЭГ вызывает значительную перестройку параметров биоэлектрической активности мозга не только в момент выполнения проб, но и в фоне-последствии. Резкое увеличение индекса медленных ритмов свидетельствует о быстром развитии утомления.

Вторая аварийная ситуация вызывала меньшие перестройки параметров ЭЭГ. В этот период в ЭЭГ в основном увеличился тета-индекс (до 59,64\%), в то время как дельта-индекс был невысоким - 10,16\%. Причём, увеличение тета-индекса произошло в основном за счёт полосы 5,7-7,8 Гц. Проба с произвольной регуляцией испытателю не удавалась из-за быстрого нарастания в ЭЭГ дельта-частот. Так, если при перемножении в уме двузначных чисел соотношения индексов основных частот были: дельта - 33,52\%, тета $-67,5 \%$, альфа $-14,69 \%$, бета $-4,66 \%$, то при «фокусировке» они перестраивались следующим образом: дельта - 58,79\%, тета $27,68 \%$, альфа $-10,40 \%$, бета - 3,10\%. Показатели слежения в первую аварию и в дни после неё были ниже, чем в обычные дни. Две ложные аварии, которые проходили во второй половине эксперимента, совпали с выраженной депрессией, развившейся у испытателя.

В этот период в ЭЭГ регистрировались высокоамплитудные медленные колебания. Максимум периодов ЭЭГ падает на диапазон частот от 1,56 до 7,8 Гц. При этой оказываются значительно подавленными не только бета-частоты, но и адьфаритм.

У испытателя М-ва (врач экипажа) во время моделирования действительных аварий отмечается некоторое нарастание тета-ритма. Повышенное содержание в
ЭЭГ тета-ритма сохраняется и в первые дни после окончания аварийной ситуации. В дни после аварий отмечается увеличение амплитуды альфа-ритма. Следует отметить, что пробы с произвольной регуляцией ЭЭГ в дни аварийных ситуаций испытатель выполнял несколько хуже, с большим напряжением нервной системы. Ухудшения качества слежения не обнаружено. Имеется некоторое снижение точности слежения в дни после прекращения аварийных ситуаций.

Во время проведения ложных аварийных ситуаций существенного изменения психофизиологического состояния у испытателя М-ва не наблюдалось. Все параметры ЭЭГ оставались такими же, как и в обычные дни. В состоянии покоя отмечалось некоторое увеличение альфа-ритма. Таким образом, по характеру изменений параметров ЭЭГ можно сделать заключение о том, что испытатель М-ов оказался наиболее устойчивым к проведённым аварийным ситуациям.

Следует также отметить, что у всех испытателей нами не было зарегистрировано реакций, подобных состоянию безнадёжности, отказу от деятельности или полной растерянности, что свидетельствует о наличии у них адекватности навыков, высокого уровня притязаний и отсутствии чувства полной беззащитности. Во всех аварийных ситуациях испытатели вели себя целенаправленно, старались выяснить и устранить причины неполадок.

Анализ полученных данных показал, что в процессе трёх- и четырёхмесячной изоляции в наземном экспериментальном комплексе с замкнутой и полностью автономной системой жизнеобеспечения (НЭК) возникают определённые изменения в функциональном состоянии центральной нервной системы испытателей.

В результате длительной социальной изоляции и сенсорной недостаточности у всех испытателей происходит смещение частотного спектра электроэнцефалограммы в сторону более медленных ритмов. Причём было обнаружено, что перестройка частоты ЭЭГ идёт не только в диапазоне альфа-ритма, как было показано ранее многими исследователями в экс- 
периментах с изоляцией испытуемых в небольших объектах [23; 24; 25], но и внутри диапазона всех ритмов ЭЭГ.

По характеру изменений частотного спектра электроэнцефалограммы в процессе длительного эксперимента можно выделить пять стадий: I - стадия повышенной возбудимости; II - стадия спада напряжения и начало дрейфа частотного спектра ЭЭГ в сторону низких частот; III - стадия постепенного нарастания выраженностей перестроек внутри всех основных ритмов ЭЭГ в сторону их более низкочастотного диапазона (снижение доминирующей частоты ритмов); IV - стадия повышения возбудимости в последние дни эксперимента и в первые дни после выхода из объекта; V - стадия постепенного восстановления исходного профиля ЭЭГ.

Первая стадия повышенной возбудимости, связанная с необычностью обстановки, проверкой технических систем, более близким знакомством с участниками эксперимента и т.д., характеризуется увеличением в ЭЭГ бета-ритма, особенно в его высокочастотном диапазоне, некоторой депрессией альфа-ритма. Одновременно в ЭЭГ регистрируется повышенное содержание тета-ритма. Эта стадия отмечалась у всех испытателей в трёх- и четырёхмесячном экспериментах. Следует отметить, что степень напряжения была неодинаковой. Так, в трёхмесячном эксперименте она была значительно выше у Ква, в четырёхмесячном у П-на, Т-ко, Г-ко. Продолжительность первой стадии составляла до двух недель.

После этого происходит снижение напряжения, в ЭЭГ испытателей увеличивается выраженность альфа-ритма, снижается бета-ритм, уменьшаются тета- и дельта-индексы. Через 10-12 дней в ЭЭГ испытателей начинаются перестройки сначала внутри бета-ритма (вторая стадия). Выраженность его высокочастотных составляющих (20,8-31,3 Гц) снижается, увеличивается диапазон более медленных частот (12,5-15,6 Гц). Начинает увеличиваться альфа-ритм в полосе 10,4-12,5 Гц. Существенных перестроек тета- и дельтаритма в этот период не отмечается.
Третья стадия характеризуется постепенным нарастанием сдвига частотного спектра ЭЭГ в сторону медленных частот. В это время в ЭЭГ отмечается общее снижение бета-индекса во всем его диапазоне, происходит замедление доминирующей частоты альфа-ритма, постепенно снижается доминирующая частота тета- и дельта-ритмов. Выраженность альфаритма и его амплитуды существенно увеличивается. В отдельных случаях пробы с переработкой информации вызывают экзальтацию альфа-ритма, а не его депрессию. Эта стадия продолжается практически вплоть до последних дней эксперимента. Перестройка амплитудно-частотных параметров ЭЭГ у всех испытателей в процессе эксперимента, как было показано выше, имеют индивидуальные особенности, хотя общая тенденция сохраняется. Так, в трёхмесячном эксперименте эти перестройки были наименьшими у М-ва, в четырёхмесячном - у К-ва, Г-ко и А-на, наибольшими у Т-ко. А-ин, Кл-ов и Г-ко принимали участие в эксперименте только в течение месяца. Следует отметить, что Ш стадия периодически прерывается фазами повышенной возбудимости и выраженной депрессии. К концу эксперимента отмечаются признаки общей астенизации организма.

Четвертая стадия, которая охватывает последние дни эксперимента и первые дни после выхода из объекта, характеризуется некоторым повышением уровня общей возбудимости. В ЭЭГ в это время отметается увеличение индекса бета-частот, некоторое повышение доминирующей частоты альфа-ритма с незначительным общим снижением альфа-индекса. Однако частотный спектр ЭЭГ по сравнению с фоновыми показателями является заметно сдвинутым в сторону более низких частот. Все испытатели, за исключением Кл-ва, который работал в НЭКе в течение месяца, вышли из объекта с изменениями ЭЭГ, характерными для IV стадии; изменения в частотном спектре ЭЭГ Кл-ва были типичными для III стадии. Это может свидетельствовать о том, что из всех испытателей только для Кл-ва окончание пребывания в НЭКе было неожи- 
данным.

На пятой стадии, которая в среднем для всех испытателей начинается через 35 дней после выхода из объекта, происходит процесс восстановления исходного профиля ЭЭГ. Следует отметить, что восстановление частотного спектра в ЭЭГ идёт в обратном порядке. При этом, как правило, однотипные перестройки происходят во всех основных ритмах ЭЭГ одновременно.

В данных экспериментах было обнаружено, что в процессе изоляции происходит существенное увеличение тетаиндекса, который значительно возрастает во время выполнения проб с переработкой информации. В дни аварийных ситуаций выраженность тета-ритма оказывается наибольшей. Согласно литературным данным $[1 ; 7 ; 12]$ увеличение тета-ритма в ЭЭГ здорового человека свидетельствует о повышении эмоционального напряжения. Кроме того, была обнаружена отчётливая связь между увеличением дельтаритма и возникновением отрицательных эмоций [13].

Таким образом, можно считать, что в процессе эксперимента происходит постепенное нарастание степени эмоционального напряжения, оказывающегося к концу эксперимента наиболее высоким.

Значительное напряжение возникает в дни аварийных ситуаций, причём у испытателя К-ва это напряжение оказывается одинаковым как в дни действительных, так и ложных аварий. Это указывает на высокую эмоциональную лабильность испытателя К-ва. Более высокое эмоциональное напряжение у К-ва, чем у А-на и М-ва, в некоторой степени может быть связано с большей его ответственностью в эксперименте как командира экипажа.

Это подтверждается результатами четырёхмесячного эксперимента, в котором К-ов не был командиром. Несмотря на больший срок изоляции, выраженность напряжения и уровень невротизации испытателя в этом эксперименте был ниже. Некоторое повышение напряжения отмечалось у испытателей в дни смены отдельных членов экипажа в четырёхмесячном эксперименте. Так, в период, когда в
НЭКе находился четвёртый член экипажа Кл-ов, уровень нервно-эмоционального напряжения у П-на и К-ва был повышенным. Особенно высокий тета-ритм, дизритмия в ЭЭГ, повышение бета-ритма отмечались в этот период у испытателя Пна. Пребывание в объекте Кл-ва сопровождалось межличностным конфликтом между отдельными членами экипажа, который по какой-то причине больше всего затронул П-на. Можно было бы думать о том, что причиной этого было увеличение численности экипажа, повлёкшее за собой повышение содержания в объекте $\mathrm{CO}_{2}$, и более форсированные режимы систем жизнеобеспечения. Последнее, естественно, потребовало от участников эксперимента, и в первую очередь от командира, более напряжённой работы по контролю за состоянием систем. Однако это предположение не является убедительным, так как при такой же ситуации в период, когда в объект вошёл испытатель Г-ко, уровень невротизации у П-на был ниже, чем в первом случае. Следовательно, конфликтность определялась не количеством экипажа, а определённой личностью. Следует отметить, что меньше всего на присутствие Кл-ва реагировал испытатель А-ин.

Что же касается самого Кл-ва, то выраженность изменений его ЭЭГ была ниже, чем у П-на и К-ва. Это ещё раз указывает на то, что именно Кл-ов являлся причиной создания конфликтных ситуаций, сам при этом мало обращая на них внимание. После выхода из НЭКа Кл-ва у всех членов экипажа отмечалось явное снижение напряжения и особенно у П-на.

Вход в НЭК испытателя Г-ко на 59 сутки эксперимента вызвал негативное отношение всех членов экипажа, на что указывает рост в ЭЭГ тета-индекса, некоторая депрессия альфа-ритма, периодически возникающая дизритмия. Наиболее высокое напряжение в этот период испытывал Т-ко.

Повышение нервно-эмоционального напряжения у всех испытателей вызвало посещение объекта исследователями в конце четвёртого месяца от начала эксперимента. Увеличение тета- и дельтаактивности в ЭЭГ основных членов эки- 
пажа указывает па повышенное нервное напряжение, сопровождающееся отрицательными эмоциями.

Можно полагать, что введение новых членов в замкнутый изолированный малочисленный коллектив воспринимается менее болезненно на первой и второй стадиях адаптации, когда ещё нет сформированных отношений внутри коллектива и адаптационные перестройки функциональных систем только начинаются. На третьей стадии, когда качал формироваться определённый адаптивный сдвиг в системах регуляции, выработались те или иные межличностные взаимоотношения и способы ухода от конфликтов, введение новых членов экипажа неизменно ведёт к нарушению сложившегося динамического стереотипа и требует его коррекции. Последнее не может произойти без нарушения устойчивости системы регуляции мозгового гомеостаза, связанной с поиском оптимальных режимов работы в новых изменившихся условиях [2; 3; 14].

Трудность «признания» нового члена экипажа обусловлена ещё и тем, что лица, которые провели в изоляции длительное время, и новичок отличаются различным функциональным состоянием мозга. Поэтому от нового члена экипажа требуется чрезвычайная осторожность в поведении, большая терпимость и деликатность во взаимоотношениях, высокий уровень самообладания. Явный негативизм, раздражительность и вспыльчивость, самоизоляция или излишняя навязчивость являются недопустимыми проявлениями со стороны нового члена экипажа, вошедшего в объект через 1-2 месяца от начала работы основных членов. На основании полученных данных (по крайней мере, в нашей методике) можно сделать заключение, что испытатель Кл-ов и, особенно испытатель Г-ко, не считались с перечисленными выше положениями, что привело к резкому увеличению нервно-эмоционального напряжения у основного состава испытателей.

\section{ЛИТЕРАТУРА}

1. Бондарев Э.В., Егоров В.А. ЭЭГ и вызванные потенциалы мозга как показа- тели функционального состояния ЦНС и анализаторов в условиях лётного труда // Информационное значение биоэлектрических потенциалов головного мозга. Л.: 1974. C. 3-4.

2. Брайнес С.Н., Свечинский В.Б. Проблемы нейрокибернетики и нейробионики. М.: Медицина, 1968. 232 с.

3. Василевский Н.Н. Дифференциальная пластичность мозга человека // Физиология человека. 1975. Т. 1. № 3. С. 469-481.

4. Волович В.Г. Человек в экстремальных условиях природной среды. М.: Мысль, 1983. 223 с.

5. Газенко О.Г., Григорьев А.И., Никогосян А.Е., Молер С.Р. Космическая биология и медицина. М.: Наука, 2001. Т. 4. $501 \mathrm{c}$.

6. Горбов Ф.Д., Мясников В.И., Яздовский В.И. О состояниях напряжения и утомления в условиях изоляции от внешних раздражителей // Журн. высш. нервн. деят. 1963. № 13. С. 585-592.

7. Золотухин А.Н. Исследования частотного спектра ЭЭГ и корреляционных связей между ЭЭГ и некоторыми физиологическими показателями при нервноэмоциональном стрессе // Информационное значение биоэлектрических потенциалов головного мозга. Л., 1974. С. 5-7.

8. Новиков В.С. Проблема адаптации в авиационной и космической медицине. СПб., 1992. 60 с.

9. Новиков В.С., Бедненко В.С., Ушаков И.Б. Основы космической физиологии // Физиология лётного труда. СПб.: Наука, 1997. C. 343-395.

10. Новиков В.С., Сороко С.И. Физиологические основы жизнедеятельности человека в экстремальных условиях. СПб.: Политехника-принт, 2017. 476 с.

11. Новиков М.А. Психофизиологические и экопсихологические аспекты межличностного взаимодействия в автономных условиях // Проблемы общении в психологии. М.: Наука, 1981. С. 18-24.

12. Симонов П.В. Высшая нервная деятельность человека. Мотивационноэмоциональные аспекты. М.: Наука, 1975. $173 \mathrm{c.}$

13. Симонов П.В., Фролов Н.В. Элек- 
троэнцефалографические симптомы эмоционального напряжения // Проблемы физиологии и патологии высшей нервной деятельности. Л.: Медицина, 1970. С. 149158.

14. Сороко С.И. Адаптационные перестройки центральных механизмов регуляции функций в экстремальных условиях Антарктиды // Тр. сов. антаркт. экспед. Л.: Гидрометеоиздат, 1975. Т. 65. С. 223-238.

15. Сороко С.И. Исследование адаптивных возможностей человека в условиях длительного пребывания в автономной системе жизнеобеспечения // Вестник образования и развития науки РАЕН. 2018. № 2. С. 56-68.

16. Фурдуй Ф.И. Стресс и здоровье. Кишинев: Штиинца, 1990. 240 с.

17. Фурдуй Ф.И., Чокинэ В.К., Глижин А.Г., Фурдуй В.Ф., Врабие В.Г., Георгиу 3.Б. Психосанокреатология, психогенный стресс и эмоции // Вестник образования и развития науки РАЕН. 2017. № 4. С. 109119.

18. Deaton J.E. The Psychology of Survival // J. Comp. Physiol. 1959. № 52. P. 309-314.
19. Levental H., Trembly G. Negative emotions and persuasion // J. Pers. 1968. V. 36. P. 154-168.

20. Rockwell D.A., Hodgson M.G., Beljan J.R., Winget C.M. Psychologic and psychophysiologic response to 105-days social isolation // Aviat. Space environ. Med. 1976. V. 47. № 10. P. 1087-1093.

21. Tyhurst J.S. Individual Reactions to Community Disaster // Amer. J. Psych., 1951. V. 107. № 10. P. 761-769.

22. Tucker G.J. Psychological aspects of sea survival // Approach. 1966. V. 11. № 9. P. 26-30.

23. Suedfeld $P$. Change in intellectual performens and in susceptibility to influence // Sensory Deprivation: Fifteen Years of Research. (Ed. by J.P. Zubek). N.Y., 1969. P. 126-166.

24. Zubek J.P., Welch G. Electroencephalographic changes after prolonged sensory and perceptual deprivation // Science, 1963. V. 139. P. 1209-1210.

25. Zubek J.P., MacNeill M. Effects of immobilization: Behavioral and EEG changes // Can. J. Psychol. 1966. V. 20. P. 316-336. 